\title{
APLICAÇÃO DE 1-METILCICLOPROPENO ASSOCIADO AO ETILENO PARA MINIMIZAR SEUS EFEITOS NA INIBIÇÃO DO AMADURECIMENTO DO MAMÃO 'GOLDEN'
}

\author{
MARCOS JOSÉ TREVISAN ${ }^{2}$, ANGELO PEDRO JACOMINO², \\ LUIS CARLOS CUNHA JUNIOR ${ }^{2}$, RENAN FERNANDES ALVES ${ }^{3}$
}

RESUMO - O objetivo deste trabalho foi estudar a fisiologia e a conservação pós-colheita de mamões 'Golden', submetidos à aplicação simultânea de 1-metilciclopropeno e etileno. Os frutos foram provenientes de cultivo comercial no Espírito Santo, no estádio de maturação 1. Os tratamentos foram compostos pelas seguintes combinações de 1-MCP $\left(\mathrm{nL} . \mathrm{L}^{-1}\right)+$ etileno $\left(\mu \mathrm{L} . \mathrm{L}^{-1}\right): 0+0 ; 100+0 ; 100+2,5 ; 100+5$ e $100+10$. Os tratamentos com 1-MCP e 1-MCP mais $2,5 \mu \mathrm{L} \mathrm{L}^{-1}$ de etileno foram os que mais retardaram a perda da firmeza e a mudança da cor. Foi observada diferença na atividade respiratória entre o controle e os demais tratamentos. Inicialmente, a produção de etileno foi maior nos frutos do controle e menor naqueles com 1-MCP, a qual aumentou a partir do $10^{\circ}$ dia. Não houve diferença no teor de sólidos solúveis entre os tratamentos. Quanto ao teor de ácido ascórbico, tratamentos com 1-MCP e 1-MCP mais 2,5 $\mu \mathrm{L}$. $\mathrm{L}^{-1}$ de etileno apresentaram os teores mais elevados. Os tratamentos apresentaram notas de aparência acima de quatro ao final do armazenamento, ou seja, com boa aparência. Com estes resultados, é possível afirmar que existe potencial de uso do 1-MPC associado ao etileno, nos estádios iniciais de maturação do mamão 'Golden', para aumentar sua vida pós-colheita.

Termos para Indexação: Carica papaya, 1-MCP, etileno, firmeza.

\section{APPLICATION OF 1-METHYLCYCLOPROPENE ASSOCIATED WITH ETHYLENE TO MINIMIZE ITS EFFECTS IN INHIBITION OF RIPENING OF 'GOLDEN' PAPAYA}

\begin{abstract}
The aim of this work was to study the physiology and postharvest conservation of 'Golden' papaya, undergone simultaneous application of 1-methylcyclopropene and ethylene. The fruits were from commercial cultivation from state of Espirito Santo, in the stage one of maturity. The treatments were the following combination of $1-\mathrm{MCP}\left(\mathrm{nL} . \mathrm{L}^{-1}\right)+$ ethylene $\left(\mu \mathrm{L} . \mathrm{L}^{-1}\right)$ of $0+0,100+0,100+2.5,100+5$ and $100+10$. Treatments of 1-MCP and 1-MCP plus ethylene $\left(2.5 \mu \mathrm{L}\right.$. $\left.\mathrm{L}^{-1}\right)$ had delayed the firmness loss and color change. There was difference in respiratory activity among the control and other treatments. At the beginning, the ethylene production was higher in non-treated fruit than in 1-MCP treated ones, which increased from the $10^{\text {th }}$ day. There was no difference in soluble solids content among the treatments. Treatments with 1-MCP and 1-MCP plus ethylene $\left(2.5 \mu \mathrm{L} . \mathrm{L}^{-1}\right)$ showed the highest levels of ascorbic acid content. The treatments showed appearance notes over of four at the end of storage, in other words, they were in good look. According to these results there is potential for use of 1-MPC associated with ethylene in the early ripening stages of 'Golden' papaya, to increase it shelf-life.
\end{abstract}

Index Terms: Carica papaya, 1-MCP, ethylene, firmness.

\footnotetext{
1(Trabalho 025-13). Recebido em: 03-01-2013. Aceito para publicação em: 06-05-2013.

${ }^{2}$ Universidade de São Paulo (USP), Escola Superior de Agricultura "Luiz de Queiroz" (ESALQ), Departamento de Produção Vegetal. Av. Pádua Dias, 11, Piracicaba-SP, Brasil, Bairro Agronomia, CP-09, CEP:13418-900, Tel.: 5519 3429-4096. E-mal: mjtrevis@usp.br, jacomino@esalq.usp.br, rfalves@esalq.usp.br.

${ }^{3}$ Universidade de São Paulo (USP), Faculdade de Ciências Farmacêuticas de Ribeirão Preto (FCFRP), Departamento de Análises Clínicas, Toxicológicas e Bromatológicas. Av. do Café s/nº Ribeirão Preto-SP, Brasil. CEP:14040-903, Tel.: 55 16 3602-0317, Fax: 55163633.1092 , E-mal: luiscarloscunha@hotmail.com
} 


\section{INTRODUÇÃO}

O Brasil é o $2^{\circ}$ produtor mundial de mamão, perfazendo cerca de $19 \%$ do total produzido (AGRIANUAL, 2011). Por tratar-se de um fruto climatérico, as transformações resultantes do amadurecimento ocorrem rapidamente após a colheita do fruto fisiologicamente maduro, desencadeadas pela produção do etileno e pelo aumento da taxa respiratória. Esse fato caracterizou-o como um fruto bastante perecível em pós-colheita (DURIGAN, 2013).

Os principais fatores que depreciam a qualidade pós-colheita do mamão são o rápido amolecimento e a elevada incidência de podridões. Dada essa alta perecibilidade, o controle do amadurecimento é fundamental para o aumento de sua vida útil após a colheita, visando ao mercado interno e à exportação.

$\mathrm{O}$ amolecimento dos frutos ocorre devido à degradação da parede celular, a qual é constituída por celulose, hemicelulose, pectinas, proteínas estruturais e lignina. As principais modificações durante o amaciamento dos tecidos são atribuídas à degradação das pectinas, que são os principais constituintes da lamela média. Esses e outros processos são desencadeados pelo etileno, que tem um importante papel durante o amadurecimento de frutos climatéricos. É ele que inicia e coordena diversos processos, tais como desenvolvimento de cor, perda de firmeza e formação do aroma (BALBOTIN et al., 2007).

O 1-metilciclopropeno (1-MCP) é um produto que tem sido utilizado na extensão da vida pós-colheita e na manutenção da qualidade de produtos vegetais, inibindo temporariamente a ação do etileno e atrasando o amadurecimento (BLANKENSHIP; DOLE, 2003). Liberado para uso em vários países, incluindo o Brasil, o 1-MCP é um produto promissor para utilização na pós-colheita de produtos vegetais. Entretanto, alguns frutos, como o mamão, a banana e a pera, entre outros, podem perder a capacidade de amadurecer quando tratados com este regulador vegetal.

Com isso, pesquisas têm sido realizadas com diversas frutas, onde o 1-MCP é aplicado junto com o etileno, com resultados promissores. Chiriboga et al. (2011) aplicaram 1-MCP associado ao etileno em peras 'Conference' e observaram que estas não apresentaram a resposta "sempre verde", devido à aplicação do 1-MCP isoladamente. No mamão 'Golden', a aplicação do 1-MCP em estádio verde também pode prejudicar seu amadurecimento, principalmente devido à perda da capacidade dos frutos em amolecer. Assim, o objetivo deste trabalho foi a aplicação do 1-MCP associado ao etileno para aumentar sua vida útil pós-colheita, sem prejudicar seu amadurecimento.

\section{MATERIAL E MÉTODOS}

Mamões da variedade 'Golden' foram colhidos em pomares comerciais, no município de Linhares-ES, levados imediatamente para a casa de embalagem, onde ocorreu a seleção dos frutos e o transporte para Piracicaba-SP, em caminhão refrigerado a $1{ }^{\circ} \mathrm{C}$. No Laboratório de Pós-Colheita de Produtos Hortícolas, foram selecionados apenas frutos no estádio 1 de maturação (até $15 \%$ da casca amarela), sem nenhum tipo de defeito. As aplicações de 1-MCP e etileno foram efetuadas simultâneamente em câmaras herméticas de 186 litros, por 12 horas, em temperatura ambiente $\left(22 \pm 1{ }^{\circ} \mathrm{C}\right.$ e $\left.90 \pm 5 \% \mathrm{UR}\right)$. Para gerar as concentrações desejadas de 1-MCP utilizou-se o produto comercial SmartFresh $(0,14 \%$ i.a.). As concentrações de etileno foram obtidas pela aplicação do gás Azetil ( $5 \%$ de etileno), o qual foi aplicado nas câmaras de tratamento, através de septos de silicone, utilizando-se de seringas. Os tratamentos foram compostos pelas seguintes combinações de 1-MCP $\left(\mathrm{nL} . \mathrm{L}^{-1}\right)+$ etileno $\left(\mu \mathrm{L} . \mathrm{L}^{-1}\right): 0+0 ; 100+0$; $100+2,5 ; 100+5$ e $100+10$.

Os frutos foram analisados quanto: a) cor da casca: determinado com colorímetro Minolta CR300 , tomando-se duas leituras em lados opostos do fruto, na região de maior diâmetro, com resultados expressos em ângulo de cor ( ${ }^{\circ}$ hue); b) firmeza da polpa: determinada com penetrômetro digital equipado com ponteira de $8 \mathrm{~mm}$, tomando-se duas leituras em lados opostos do fruto sem a casca, na região de maior diâmetro, sendo os resultados expressos em Newtons $(\mathrm{N})$; c) teor de sólidos solúveis: determinado em refratômetro digital marca Atago, modelo Pallete-101, sendo os resultados expressos em ${ }^{\circ}$ Brix; d) teor de ácido ascórbico expresso em mg de ácido ascórbico por $100 \mathrm{~g}$ de polpa. Estas avaliações foram realizadas no início e no final do armazenamento, utilizando-se de 5 repetições de 2 frutos.

Para a produção de etileno e dióxido de carbono $\left(\mathrm{CO}_{2}\right)$, os frutos foram colocados em recipientes herméticos de vidro com capacidade de $1.700 \mathrm{~mL}$, previamente expostos às condições de temperatura $\mathrm{e}$ umidade do experimento. Após 1 hora, amostras de $1 \mathrm{~mL}$ de gás foram coletadas dos recipientes através de um septo de silicone, com auxílio de uma seringa (Hamilton, Gastight, Nevada, EUA) e analisadas em cromatógrafo marca Thermo Finnigan, modelo Trace $2.000 \mathrm{GC}$, equipado com detector de ionização de chama (FID) a $250{ }^{\circ} \mathrm{C}$, injetor a $120^{\circ} \mathrm{C}$ e coluna Porapack $\mathrm{N}$ de 1,8 metro a $120^{\circ} \mathrm{C}$, com nitrogênio como gás de arraste $\left(30 \mathrm{~mL} \cdot \mathrm{min}^{-1}\right)$. Para a análise da 
atividade respiratória, foi utilizada a mesma configuração do etileno, porém a coluna foi de 4,0 metros, com metanador a $350{ }^{\circ} \mathrm{C}$. Essa quantificação deu-se pela diferença entre a concentração gasosa inicial dentro dos frascos no momento do fechamento e após 1 hora, sendo expressas em $\mathrm{mL} \mathrm{CO} \mathrm{Cg}_{2} \cdot \mathrm{kg}^{-1} \cdot \mathrm{h}^{-1}$ e $\mu \mathrm{L} \mathrm{C}_{2} \mathrm{H}_{4} \mathrm{~kg}^{-1} \cdot \mathrm{h}^{-1}$, respectivamente. Essas análise foram realizadas diariamente, utilizando-se de 5 repetições de 1 fruto.

$\mathrm{O}$ delineamento experimental foi o inteiramente ao acaso, com 5 repetições por tratamento, sendo considerado cada fruto uma repetição. Os resultados obtidos foram submetidos à análise de variância, e as médias, comparadas pelo teste de Tukey, a $5 \%$ de probabilidade e análise do erro-padrão. O programa utilizado nestas análises foi o SISVAR.

\section{RESULTADOS E DISCUSSÃO}

A firmeza dos frutos tratados com 1-MCP mais etileno, na dose de $10 \mu \mathrm{L}$. $\mathrm{L}^{-1}$, não diferiu do controle (Tabela 1). Lelièvre et al. (1997) mencionaram que a perda de firmeza está relacionada ao etileno, que ativa enzimas pectinolíticas que transformam a pectina insolúvel em solúvel. An e Paull (1990) relataram em seus estudos que a aplicação exógena de $100 \mathrm{~mL}$. L ${ }^{-1}$ de etileno estimulou o amadurecimento de mamões, evidenciado pelo amolecimento da polpa, degradação da clorofila e síntese de carotenoides na casca.

O 1-MCP tem sido usado no tratamento de diversas espécies vegetais, com a finalidade de prolongar a vida útil pós-colheita destas espécies, com excelentes resultados, como é o caso da maçã. No entanto, o amadurecimento de frutos climatéricos pode ser fortemente ou irreversivelmente reprimido em resposta à aplicação do 1-MCP, principalmente quando este é aplicado no pré-climatérico, quando a produção de etileno ainda é baixa (ZHANG et al., 2009).

Nos frutos onde foi aplicado apenas 1-MCP, a firmeza permaneceu elevada $(127,87 \mathrm{~N})$ após 12 dias de armazenamento a $22^{\circ} \mathrm{C}$. Estes frutos estavam inaptos para o consumo. Aqueles que receberam 1-MCP mais etileno, nas doses de 2,5 e $5 \mu \mathrm{L}$. L${ }^{-1}$,apresentaram valores de firmeza de 48 e $35,46 \mathrm{~N}$, respectivamente, no $10^{\circ}$ e $6^{\circ}$ dias de armazenamento. Os frutos do controle estavam com firmeza 7,31 N, no $6^{\circ}$ dia de armazenamento (Tabela 1 ). O tratamento de bananas com etileno antecipou os eventos relacionados ao amadurecimento, enquanto estes eventos foram atrasados pelo tratamento com 1-MCP (MAINARD et al., 2006). Resultados de retenção da firmeza causada pela aplicação do 1-MCP também foram relatados por Fabi et al. (2009) e Jacomino et al. (2002) em mamão, Tibola et al. (2005) em caqui e Zhang et al. (2009) em tomate.

Quanto à cor da casca, em todos os tratamentos, os frutos atingiram a coloração amarela; entretanto, nos tratamentos apenas com 1-MCP e 1-MCP mais $2,5 \mu \mathrm{L} . \mathrm{L}^{-1}$ de etileno, isto ocorreu respectivamente aos 12 e 10 dias após a aplicação dos tratamentos (Tabela 1). Jacomino et al. (2002) também verificaram retenção da cor verde da casca, em resposta ao tratamento com 1-MCP em mamão 'Sunrise Solo'.

Em todos os tratamentos, os frutos mostraram notas de aparência superior a quatro, o que significou que todos estavam com boa aparência ao final do armazenamento (Figura 1). Leverentz et al. (2003) relataram que frutos com amadurecimento retardado pelo 1-MCP são mais resistentes à deterioração por doenças e, por consequência, têm melhor aparência. No entanto, Jiang et al. (2001) afirmaram que dosagens elevadas de 1-MCP aceleraram o desenvolvimento de doenças em morangos, devido à inibição da síntese da enzima fenilalanina-amônio-liase (PAL) e de compostos fenólicos.

A atividade respiratória dos mamões do tratamento-controle foi mais elevada que a dos demais tratamentos até o final de seu armazenamento, no $6^{\circ}$ dia (Figura 2). Já o tratamento em que foi aplicado apenas 1-MCP mostrou a menor atividade, devido ao bloqueio do etileno pelo 1-MCP. Nos trabalhos conduzidos por Sañudo-Barajas et al. (2009) com mamão, foram observados resultados semelhantes aos verificados neste trabalho. Os pesquisadores registraram que a taxa inicial de respiração foi menor em frutos tratados com 1-MCP, porém este efeito não foi observado quando o inibidor foi aplicado depois do etefon. Toivonen (2008) mencionou que a respiração e a produção de etileno estão diretamente ligadas à aplicação de 1-MCP, os quais são afetados por este composto.

A produção de etileno no início foi maior nos frutos do controle e menor nos que foram tratados apenas com 1-MCP, permanecendo assim até o $6^{\circ}$ dia (Figura 3). O tratamento apenas com 1-MCP teve significativo aumento a partir do $7^{\circ}$ dia, com produção de $14,66 \mu \mathrm{L} \mathrm{C}_{2} \mathrm{H}_{4} \cdot \mathrm{kg}^{-1} \cdot \mathrm{h}^{-1}$ no $12^{\circ}$ dia. Entretanto, a firmeza destes frutos permaneceu elevada para o consumo, mesmo com a elevação da produção de etileno (Tabela 1). Isso mostrou que os frutos retomaram a produção de etileno após alguns dias da aplicação do 1-MCP, porém seu aumento foi muito tardio em relação aos frutos do controle, prejudicando o amadurecimento dos frutos deste tratamento.

É provável que o estímulo à produção de 
etileno seja devido à perda do feedback negativo da sua biossíntese (WATKINS, 2006). Entretanto, neste trabalho, mesmo com a retomada da produção de etileno, o fruto não conseguiu completar seu amadurecimento. Isto ocorreu, provavelmente, devido à perda do momento entre essa produção autocatalítica, que foi atrasada pela aplicação do 1-MCP, e a capacidade que o fruto tem de perceber o etileno. Essa falha na habilidade do fruto em recuperar a capacidade de amolecimento da polpa, segundo estudos realizados por Paull e Chen (1983), pode estar relacionada às enzimas poligalacturonase (PG) e xilanase, que, de acordo com relatos dos pesquisadores, têm um pico de atividade quando o mamão está com 40 a $60 \%$ da epiderme amarela. Os pesquisadores também confirmaram em outro estudo (PAULL; CHEN, 1991), que o RNA mensageiro para estas enzimas em mamões foi produzido por um curto período de tempo durante $o$ amadurecimento do fruto.

O teor de sólidos solúveis foi próximo em todos os tratamentos (Tabela 1), com valor inicial de $8,59{ }^{\circ}$ Brix, alterando-se pouco durante todo o armazenamento. Jacomino et al. (2007) também avaliaram mamões ‘Golden' quanto ao teor de sólidos solúveis em frutos com e sem 1-MCP e relataram que o 1-MCP não afetou o teor. A pouca variação no teor de sólidos solúveis durante o amadurecimento do mamão 'Golden' ocorreu devido ao fato de que esta fruta, segundo relatos de Jacomino et al. (2007), não apresenta quantidade significativa de amido para ser hidrolisado durante o processo de amadurecimento.

Selvaraj et al. (1982) relatam que o teor de ácido ascórbico em mamões aumenta com o amadurecimento. Neste trabalho, não houve aumento significativo nos frutos do controle durante o amadurecimento, que passou de 54,53 mg. $100 \mathrm{~g} \mathrm{polpa}^{-1}$ no início para $55,78 \mathrm{mg} .100 \mathrm{~g} \mathrm{polpa}^{-1}$ no final. Esse aumento foi mais significativo nos tratamentos em que foram aplicados apenas 1-MCP e 1-MCP mais $2,5 \mu \mathrm{L} . \mathrm{L}^{-1}$ de etileno (Tabela 1). Doll Hojo et al. (2009) verificaram que o uso do 1-MCP em mangas 'Palmer' frigoconservadas reduziu a perda de ácido ascórbico. Isso provavelmente deve ter ocorrido devido ao atraso no amadurecimento dos frutos, com queda na atividade respiratória e na produção de etileno, com menor gasto de substratos, em resposta à aplicação do 1-MCP.

TABELA 1- Firmeza da polpa, cor da casca, teor de sólidos solúveis (SS) e de ácido ascórbico (AA) de mamões ‘Golden', submetidos à aplicação de 1-MCP e etileno, e armazenados por 12 dias a $22^{\circ} \mathrm{C}$.

\begin{tabular}{|c|c|c|c|c|c|c|}
\hline \multicolumn{2}{|c|}{ Tratamentos } & \multicolumn{4}{|c|}{ Variáveis analisadas } & \multirow{2}{*}{$\begin{array}{c}\text { Tempo de } \\
\text { conservação } \\
\text { (no de dias) }\end{array}$} \\
\hline $\begin{array}{l}\text { 1-MCP } \\
\left(n L . L^{-1}\right)\end{array}$ & $\begin{array}{l}\text { Etileno } \\
(\mu \text { L.L- })\end{array}$ & $\begin{array}{l}\text { Firmeza } \\
(\mathbf{N})\end{array}$ & $\begin{array}{c}\text { Cor da Casca } \\
\left({ }^{\circ} h u e\right)\end{array}$ & $\begin{array}{c}\text { SS } \\
\left({ }^{\circ} \text { Brix }\right)\end{array}$ & $\begin{array}{c}\mathrm{AA} \\
\left(\mathrm{mg.100} \mathrm{g} \mathrm{polpa}^{-1}\right)\end{array}$ & \\
\hline 0 & 0 & $7,31 \mathrm{c}$ & $83,17 \mathrm{~b}$ & $9,25 \mathrm{a}$ & $55,78 \mathrm{~b}$ & 6 \\
\hline 100 & $\mathbf{0}$ & $127,87 \mathrm{a}$ & $81,95 b c$ & $9,66 \mathrm{a}$ & $71,85 \mathrm{a}$ & 12 \\
\hline 100 & 2,5 & $48,00 \mathrm{~b}$ & $80,92 \mathrm{c}$ & $9,30 \mathrm{a}$ & $72,96 a$ & 10 \\
\hline 100 & 5 & $35,46 b$ & $86,24 a$ & $10,52 \mathrm{a}$ & $67,18 \mathrm{ab}$ & 6 \\
\hline 100 & 10 & $11,92 \mathrm{c}$ & $81,99 b c$ & $9,46 \mathrm{a}$ & $67,02 \mathrm{ab}$ & 6 \\
\hline \multicolumn{2}{|c|}{ dms } & 15,60 & 2,21 & 1,38 & 11,76 & -- \\
\hline \multicolumn{2}{|c|}{ CV $(\%)$} & 18,88 & 2,50 & 8,02 & 10,84 & -- \\
\hline
\end{tabular}

*Médias seguidas de pelo menos uma letra igual para cada variável não diferem entre si, pelo teste de Tukey $(\mathrm{p} \leq 0,05)$ 

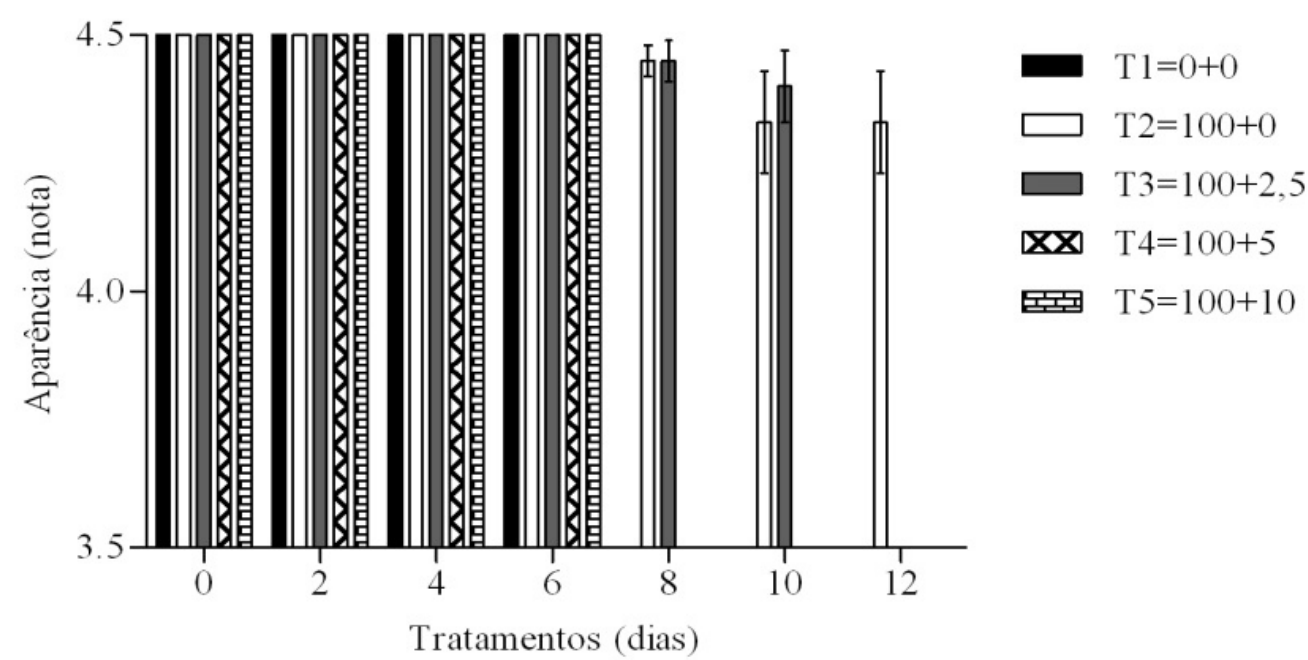

FIGURA 1 - Aparência de mamões 'Golden', submetidos aos tratamentos com 1-MCP e etileno, em diferentes concentrações, armazenados por 12 dias a $22^{\circ} \mathrm{C}$. Notas: $5=$ excelente; $4=$ bom; $3=$ regular; $2=$ ruim; $1=$ péssimo. As barras verticais indicam o erro-padrão da média $(\mathrm{n}=10)$. T1 a T5 indicam os tratamentos com 1-MCP $\left(n L . L^{-1}\right)+$ etileno $\left(\mu \mathrm{L} . \mathrm{L}^{-1}\right)$.

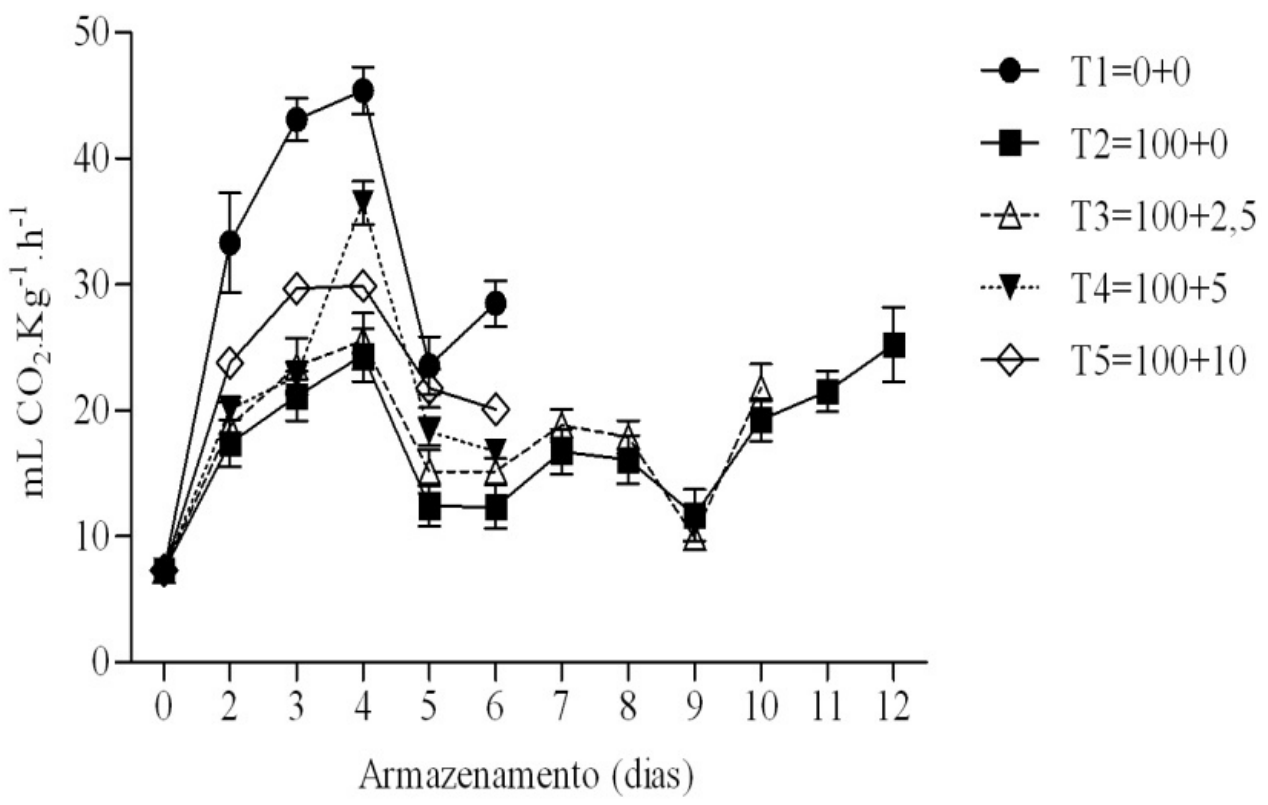

FIGURA 2 - Atividade respiratória de mamões 'Golden', submetidos aos tratamentos com 1-MCP e etileno, armazenados por 12 dias a $22^{\circ} \mathrm{C}$. As barras verticais representam o erro-padrão da média $(\mathrm{n}=5)$. T1 a T5 indicam os tratamentos com 1-MCP $\left(n L . L^{-1}\right)+$ etileno $\left(\mu \mathrm{L} . \mathrm{L}^{-1}\right)$. 


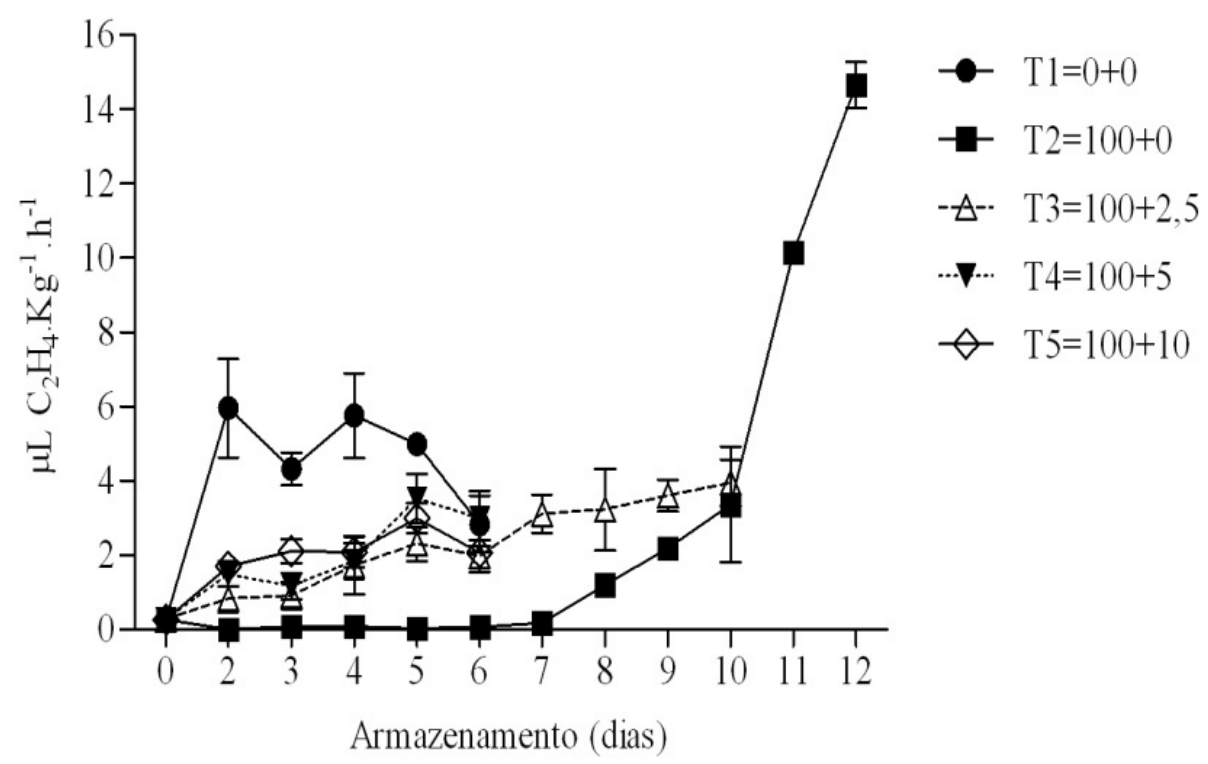

FIGURA 3 - Produção de etileno de mamões 'Golden', submetidos aos tratamentos com 1-MCP e etileno, armazenados por 12 dias a $22{ }^{\circ} \mathrm{C}$. As barras verticais indicam o erro-padrão da média $(\mathrm{n}=5)$. T1 a T5 indicam os tratamentos com 1-MCP $\left(n L . L^{-1}\right)+$ etileno $\left(\mu \mathrm{L} . \mathrm{L}^{-1}\right)$.

\section{CONCLUSÃO}

O 1-MCP (100 nL. L-1) aplicado em associação ao etileno $(2,5 \mu \mathrm{L}$. L-1) permite ampliar o tempo de conservação do mamão 'Golden', sem prejudicar seu amadurecimento. O uso do 1-MPC em associação ao etileno nos estádios iniciais de maturação aumenta a vida útil pós-colheita do mamão 'Golden'.

\section{REFERÊNCIAS}

AGRIANUAL: anuário da agricultura Brasileira. São Paulo: FNP, 2011.

AN, J.; PAULL, R.E. Storage temperature and ethylene influence on ripening of papaya fruit. Journal of the American Society for Horticultural Science, Alexandria, v.115, p.949-953, 1990.

BALBONTÍN, C.; GAETE-EASTMAN, C.; VERGARA, M.; HERRERA, R.; MOYA-LÉON, M.A. Treatment with 1-MCP and the role of ethylene in aroma development of mountain papaya fruit. Postharvest Biology and Technology, Amsterdam, v.43, p.67-77, 2007.
BLANKENSHIP, S.M.; DOLE, J.M. 1-Methylcyclopropene: a review. Postharvest Biology and Technology, Amsterdam, v.28, p.125, 2003.

CHIRIBOGA, M.A.; SCHOTSMANS, W.C.; LARRIGAUDIÈRE, C.; DUPILLE, E.; RECASENS, I. How to prevent ripening blockage in 1-MCPtreated 'Conference' pears. Journal of Science and Food Agriculture, Lleida, v.10, n.15, p.1781-1788, 2011.

DOLL HOJO, E.T.; ABREU, C.M.P. de; ASMAR, S.A.; HOJO, R.H.; CÔRREA, A.D.; VILAS BOAS, E.V.B. Avaliação da qualidade de manga 'Palmer' tratadas com 1-metilciclopropeno e armazenada sob refrigeração e condição ambiente. Revista Brasileira de Fruticultura, Jaboticabal, v.31, n.1, p.28-38, 2009.

DURIGAN, J.F. Pós colheita de frutas. Revista Brasileira de Fruticultura, Jaboticabal, v.35, n.2. p.i, 2013.

FABI, J.P.; CORDENUNSI, B.R.; SEYMOUR, G.B.; LAJOLO, F.M.; NASCIMENTO, J.R.O. Molecular cloning and characterization of a ripening-induced polygalacturonase related to papaya fruit softening. Plant Physiology and Biochemistry, Bologne, v.47, n.11/12, p.1075-1081, 2009. 
JACOMINO, A.P.; KLUGE, R.A.; BRACKMANN, A.; CASTRO, P.R.C. Amadurecimento e senescência de mamão com 1-metilciclopropeno. Scientia Agricola, Piracicaba, v.59, n.2, p.303-308, 2002.

JACOMINO, A.P.; TREVISAN, M.J.; ARRUDA, M.C. de; KLUGE, R.A. Influence of the interval between harvest and 1-methylcyclopropene application on papaya ripening. Revista Brasileira de Fruticultura, Jaboticabal, v.29, n.3, p.456-459, 2007.

JIANG, Y.; JOYCE, D.C.; TERRY, L. A. 1-Methylcyclopropene treatment affects strawberry fruit decay. Postharvest Biology and Technology, Amsterdam, v.23, n.3, p.227-232, 2001.

LELIÈVRE, J.M.; LATCHÉ, A.; JONES, B.; BOUZAYEN, M.; PECH, J.C. Ethylene and fruit ripening. Physiologia Plantarum, Copenhagen, v.101, p.727-739, 1997.

LEVERENTZ, B.; CONWAY, W.S.; JANISIEWICZ, W.J.; SAFNER, R.A.; CAMP, M.J. Effect of combining MCP treatment, heat treatment and biocontrol on the redution of postharvest decay of 'Golden Delicious' apples. Postharvest Biology and Technology, Amsterdam, v.27, n.3, p.221-233, 2003.

MAINARDI, J.A.; PURGATTO, E.; VIEIRA JÚNIOR, A.; BASTOS, W.A.; CORDENUNSI, B.R.; NASCIMENTO, J.R.O.; LAJOLO, F.M. Efeitos do etileno e do 1-MCP sobre a expressão gênica e atividade da amido fosforilase plastidial durante o amadurecimento da banana. Journal of Agricultural and Food Chemistry, Washington, v.54, n.19, p.7294-7299, 2006.
PAULL, R.E.; CHEN, N.J. Heat shock response in field grown papaya. Journal of the American Society for Horticultural Science, Alexandria, v.115, p.623-631, 1991.

PAULL, R.E.; CHEN, N.J. Postharvest variation in cell wall-degrading enzymes of papaya (Carica papaya L.) during fruit ripening. Plant Physiology, Rockville, v.72, p.382-385, 1983.

SAÑUDO-BARAJAS, J.A.; LABAVITCH, J.; GREVE, C.; OSUNA-ENCISO, T.; MUY-RANGEL, D.; SILLER-CEPEDA, J. Cell wall disassembly during papaya softening: role of ethylene in changes in composition, pectin-derived oligomers (PDOs) production and wall hydrolases. Postharvest Biology and Technology, Amsterdam, v.51, p.158167,2009

SELVARAJ, Y.; SUBRAMANYAN, M.D.; IYER, C.P.A. Changes in the chemical composition of four cultivar of papaya (Carica papaya L.) during growth and development. Journal of Horticultural Science, Bengalore, v.5, p.135-143, 1982.

TIBOLA, C.S.; LUCHETTA, L.; ZANUZO, M.R.; SILVA, P.R. da; FERRI, V.C.; ROMBALDI, C.V. Inibição da ação do etileno na conservação de caquis (Diospyrus kaki L.). Revista Brasileira de Fruticultura, Jaboticabal, v.27, n.1, p.36-39, 2005.

TOIVONEN, P.M.A. Application of 1 -methylcyclopropene in fresh-cut/minimal processing systems. HortScience, Alexandria, v.43, p.102-105, 2008.

WATKINS, C.B. The use of 1-methylcyclopropene (1-MCP) on fruits and vegetables. Biotechnology Advances, Amsterdam, v.24, n.4, p.389-409, 2006.

ZHANG, Z.; HUBER, D.J.; HURR, B.M.; RAO, J. Delay of tomato fruit ripening in response to 1 -methylcyclopropene is influenced by internal ethylene levels. Postharvest Biology and Technology, Gainesville, v.54, p.1-8, 2009. 